\title{
Nanopatterned Polymer Molds Using Anodized Aluminum Templates for Anti-Reflective Coatings
}

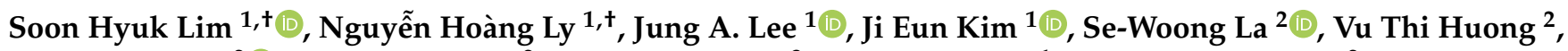 \\ Thi-Giang Tran ${ }^{2}\left(\mathbb{D}\right.$, Ngoc Thanh Ho ${ }^{2}$, Seung Man Noh ${ }^{3, *}$, Sang Jun Son ${ }^{1, *}$ and Sang-Woo Joo ${ }^{2, *}$
}

1 Department of Chemistry, Gachon University, Seongnam 13120, Korea; 2952305@naver.com (S.H.L.); nguyenhoangly2007@gmail.com (N.H.L.); sb52431@naver.com (J.A.L.); wnpwnp81@naver.com (J.E.K.)

2 Department of Chemistry, Soongsil University, Seoul 06978, Korea; sktpdnd9668@daum.net (S.-W.L.); huongvu172018@gmail.com (V.T.H.); trangianghup@gmail.com (T.-G.T.); ngocthanhkd94@gmail.com (N.T.H.)

3 Research Center for Green Fine Chemicals, Korea Research Institute of Chemical Technology, Ulsan 44412, Korea

* Correspondence: smnoh@krict.re.kr (S.M.N.); sjson@gachon.ac.kr (S.J.S.); sjoo@ssu.ac.kr (S.-W.J.); Tel.: +82-2-820-0434 (S.-W.J.)

+ S.H.L. and N.H.L. contributed equally to this work.

Citation: Lim, S.H.; Ly, N.H.; Lee, J.A.; Kim, J.E.; La, S.-W.; Huong, V.T.; Tran, T.-G.; Ho, N.T.; Noh, S.M.; Son, S.J.; et al. Nanopatterned Polymer Molds Using Anodized Aluminum Templates for Anti-Reflective Coatings. Polymers 2021, 13, 3333. https: / /doi.org/10.3390/ polym13193333

\section{Academic Editors:}

Thanh-Danh Nguyen, Lilia Sabantina and Han-Yu Hsueh

Received: 29 August 2021

Accepted: 24 September 2021

Published: 29 September 2021

Publisher's Note: MDPI stays neutral with regard to jurisdictional claims in published maps and institutional affiliations.

Copyright: (c) 2021 by the authors. Licensee MDPI, Basel, Switzerland. This article is an open access article distributed under the terms and conditions of the Creative Commons Attribution (CC BY) license (https:// creativecommons.org/licenses/by/ $4.0 /)$.

\begin{abstract}
This work introduces a facile geometry-controlled method for the fabrication of embossed and engraved polymeric moth-eye-inspired nanostructures in imprinting molds using anodic aluminum oxide (AAO) templates, resulting in a novel anti-reflective transparent coating. The moth-eye nanostructures are prepared directly on the surface of a flexible polyethylene terephthalate (PET) substrate. As a prerequisite procedure, a UV-curable polyurethane acrylate resin is spun on the PET. The shape of the moth-eye nanostructures can then be adjusted by controlling the size and shape of the nanopores in the AAO templates. Both embossed and concaved polymer moth-eye nanostructures were successfully mounted on a PET substrate. Embossed polymer replica molds were prepared using the AAO master templates in combination with an imprinting process. As revealed by field-emission electron microscope (FE-SEM) images, conical nanopatterns in the AAO template with a diameter of $\sim 90 \mathrm{~nm}$ and a depth of $\sim 100 \mathrm{~nm}$, create a homogeneous embossed morphology in the polymer moth-eye nanostructure. The polymeric molds with the depths of 300 and $500 \mathrm{~nm}$ revealed the amalgamated structures in their apexes. In addition, a dip-imprinting process of the polymeric layers was implemented to yield a concaved mold by assembly on the surface of the $100 \mathrm{~nm}$ embossed polymer mold substrate. Considering that the embossed structures may be crumbled due to their protuberant shapes, the concaved geometries can have an advantage of stability in a certain application concerning physical degradation along with a higher transmission by $\sim 2 \%$, despite somewhat nonuniform structure. The experimental and theoretical results of this study indicate that this polymer layer has the potential for use in anti-reflective coating applications in transparent films.
\end{abstract}

Keywords: nanocone pattern; transparent coating films; anodized aluminum oxide; anti-reflective surfaces; moth-eye structures; shape-controlled fabrication

\section{Introduction}

Nanostructures have been used for various applications in chemistry and materials science [1]. Nanotemplates have recently emerged as potential platforms for the fabrication of functional materials with many uses in multiple fields, including transparent coatings [2] and solar cells [3]. The bionic prototypes and antireflection principles inspired by nature are discussed in the recent review [4]. Hexagonal nipple-array of subwavelength conical nanostructures have a diameter of ca. $100 \mathrm{~nm}$ and can provide broadband anti-reflectivity to enhance photon collection capability [5]. The shapes and sizes appeared to affect reflectivity performance [6-8]. Several nanostructures have been developed for efficiently hydrophobic 
and anti-reflective coating materials [9-11]. To obtain the anti-reflection effects of moth-eyelike nanostructures, a high- density array with homogeneous morphology are prerequisites for practical applications.

Recent studies have demonstrated several methodologies to fabricate moth-eye nanostructures including the Langmuir-Blodgett technique [12], lithography $[9,13,14]$, imprinting processes [15], double replication of a silicon master [10], dip-coating solid silica nanoparticles [11], and a combination of ultrasonic vibration demolding and precision hot embossing [16]. In particular, there has been a series of studies on the AAO templateassisted synthesis of moth-eye-inspired nanostructures reporting significant properties such as superhydrophobicity [17], anti-reflectivity [18,19], and ultrasensitive substrates for surface-enhanced Raman scattering-based detection $[4,20]$. Such templates represent a low-cost and facile process to provide an alternative to the above-mentioned techniques.

Polymer-based materials have attracted considerable attention due to their flexibility, hydrophobicity, and universal applicability [21-25]. Several studies have been conducted around the development of novel polymer layers, including poly(methyl methacrylate) coatings to enhance the light amplification of perovskite films [26] and superamphiphobic properties of silica-fluoropolymer coating layer [27]. In addition, near-surface mounting methods have been investigated in relation to fiber reinforced polymer strengthening $[21,28]$ and reinforcing concrete bridges $[23,29]$. These studies have demonstrated the importance of homogeneous morphology in polymeric patterns. Based on the previous routine procedures, there is a practical need to develop the fabrication of various polymerbased moth-eye nanostructures, through direct imprinting using geometry-controlled AAO templates in building master molds for patterned polymer materials. Although the preparation of moth-eye nanostructures with noble metal materials and AAO platforms has been widely investigated, the novel technique of fabricating concave polymer-based nanostructures requires further research to implement this into practical applications.

In this work, an anti-reflective film of polymeric moth-eye nanostructures was assembled on the PET surface, by removing the AAO template. This flexible nanostructured film, with a thickness of c.a. $100 \mathrm{~nm}$, exhibited not only the superhydrophobic properties but also high transmission in the visible and near-infrared region. AAO is a versatile nanostructure material due to its economical and reproducible qualities. Since AAO platforms have been successfully employed in preparing nanostructured metal materials with high uniformity in numerous shapes, including wires, tubules, rods, and dots, the present method of combining an AAO template with the UV imprinting process appears to be a convenient, straightforward, low-cost, and reusable method to build moth-eye-inspired polymeric nanostructures with a promise for anti-reflective coating applications.

\section{Materials and Methods}

\subsection{Materials}

Aluminum foil (99.99\%) was obtained from Alfa Aesar (Karlsruhe, Germany). Perchloric acid $(70 \%)$, ethyl alcohol anhydrous $(99.9 \%)$, oxalic acid $(99.5 \%)$, chromium oxide (IV) (99\%), phosphoric acid (99.5\%), and acetone (99.5\%) were purchased from Daejung Chemicals (Siheung, Korea). The fluorine hydrophobic demolding reagent, UVcuring polyurethane acrylate resins, and additives were synthesized by referring to the recent report [30].

\subsection{Preparation and Surface Modification of Moth-Eye-Inspired Polymer Nanostructures}

Annealed aluminum foil was degreased using a Branson 8510 sonicator (Brookfield, CT, USA) in acetone for $1 \mathrm{~h}$ and then electro-polished with a mixture of perchloric acid and ethanol $(1: 5, v / v)$ for $6 \mathrm{~min} 30 \mathrm{~s}$ at $0{ }^{\circ} \mathrm{C}$ and $15 \mathrm{~V}$. These templates were first-anodized in $0.3 \mathrm{M}$ oxalic acid solution under the condition of $10^{\circ} \mathrm{C}$ and $40 \mathrm{~V}$ for $8 \mathrm{~h}$. The nonuniform aluminum oxide membrane that resulted from the first-anodization was performed by a mixture solution of chromium oxide (1.8 wt.\%) and phosphoric acid ( $6 \mathrm{wt} . \%)$ at $60{ }^{\circ} \mathrm{C}$ for $5 \mathrm{~h}$. The depths and pore diameters in nanocone-shape AAO molds could be controlled 
by varying the 2 nd anodization and pore widening times from $17-83 \mathrm{~s}$ and $3-5 \mathrm{~min}$, respectively. To obtain a conical nanopore of $\sim 100 \mathrm{~nm}$ in depth and $\sim 90 \mathrm{~nm}$ in diameter, the templates were secondly anodized under the same conditions as the first-anodization for $15 \mathrm{~s}$. The templates were then immersed in an aqueous solution of phosphoric acid (5 wt.\%) under the condition of $30^{\circ} \mathrm{C}$ for $5 \mathrm{~min}$. The processes of the second anodization and pore-widening were repeated six times.

Next, 10 drops of the fluorine-containing surface-treatment solution were applied to the bottom of either a beaker or glass petri dish, and the AAO templates with conical shape nanopores were placed on the top for an efficient demolding. In order to evaporate the solvent on the surface of the template, the samples were placed in an oven at $130{ }^{\circ} \mathrm{C}$ for $30 \mathrm{~min}$. They were then allowed to cool at room temperature and washed twice with ethanol. Following this surface modification of the AAO mold with the polymer solution, the template was placed on the resin on the PET film and rolled to fabricate a polymer layer as thin as possible, which was then cured by the UV irradiation through the upward facing PET substrate for $30 \mathrm{~s}$. The AAO template was then removed to reveal a polymer layer on the PET replicating the moth-eye nanopatterns of the template. This was cured with UV for another $30 \mathrm{~s}$.

Figure 1 illustrates the fabrication process of a moth-eye nanostructure in polymer resin on a PET substrate using an AAO template as an imprinting mold. In the first step, a high-purity aluminum foil was anodized in a two-stage process leading to conical nanopore array inside the AAO template. Each nanocone was specifically designed with a $90 \mathrm{~nm}$ diameter and a $100 \mathrm{~nm}$ depth. Subsequently, the AAO platform was reacted with a polymer to obtain a lower surface energy than the original material. The AAO surface could deform the nanostructure during the template removal and the UV curing. The shape and size of the nanopore array inside the AAO template depended on the conditions of each anodization phase. This method was performed with the second anodization under the same conditions as the first for $15 \mathrm{~s}$. The morphology characterization of the AAO templates was conducted by FE-SEM. This soft molding technique combined with UV imprinting process exhibited an efficient fabrication of flexible nanostructures [31]. The method not only produces patterns with the advantage of continuous production over areas as large as several centimeters but is also a particularly high-speed manufacturing process. The combination of UV imprinting and demolding to form a transparent film of polymeric moth-eye nanostructures on a PET substrate is illustrated in Figure 1.

(a)
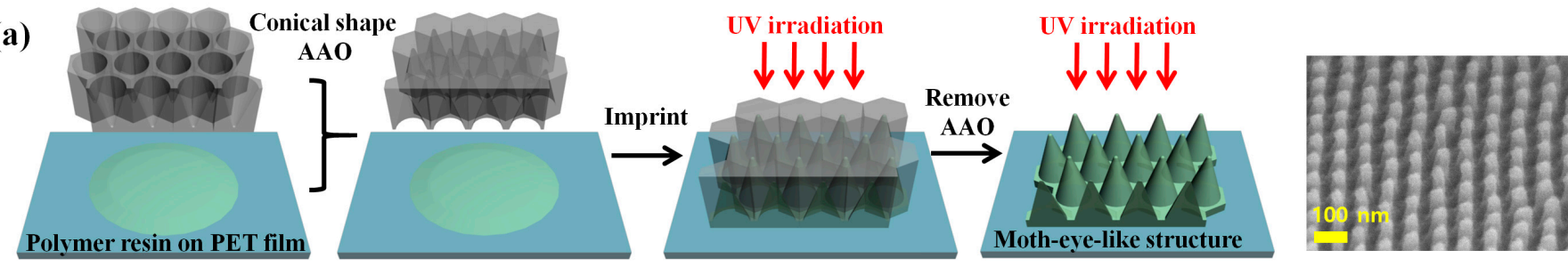

(b)
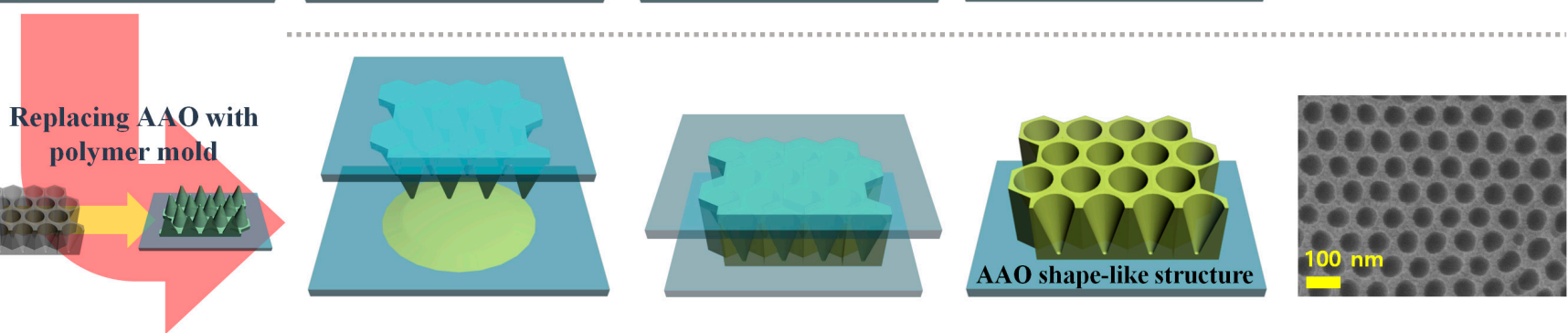

Figure 1. Schemes of UV-curable polyurethane acrylate moth-eye-like nanostructures on PET substrates for (a) embossed and (b) concaved polymer molds. 


\subsection{Physicochemical Characterization and COMSOL Multiphysics Simulation}

AAO templates and moth-eye-like nanostructures of polymer layers were examined via a JEOL JSM-7500F FE-SEM (Tokyo, Japan). Contact angle images were obtained by a SEO Phoenix-10 analyzer (Suwon, Korea). UV-curing was performed with a Lightzen $60 \mathrm{PH}$ portable device. (Gunpo, Korea). The optical transmission measurements were conducted using a Shimadzu 2450 spectrophotometer (Tokyo, Japan). A COMSOL simulation (Burlington, MA, USA) was performed with a modification for an organic material by referring to the previous work on the semiconductor materials [8]. The absorption and scattering spectra of polymer-based moth-eye-like nanostructure were calculated using the package of COMSOL Multiphysics Version 5.3a. Each nanocone had a $90 \mathrm{~nm}$ diameter and a $100 \mathrm{~nm}(300 \mathrm{~nm}, 500 \mathrm{~nm})$ depth with a refractive index of 1.5. This package was also used to simulate the absorption and scattering spectra of the moth eye structure (MES) with the incident light. The geometric parameters of the nanostructure were realized by the 'parameter' function in 'global definition', which could easily change the parameter settings of the entire model. The single hexagonal structure of MES with the 6 tips was chosen to represent the MES array. The length and the tip radius were $100 \mathrm{~nm}$ and $45 \mathrm{~nm}$, respectively with the substrate thickness of $100 \mathrm{~nm}$. This model assumed that the real part of the refractive index of air was 1 and the imaginary part of the refractive index was 0 . The refractive index of MES was set to be 1.5. The length of the MES substrate was introduced into the middle of an air spherical domain $(\varphi=2 \mu \mathrm{m})$ to avoid reflection by a perfectly matched layer boundary condition. The incident light wavelength range of this simulation model was $400 \mathrm{~nm}$ to $2000 \mathrm{~nm}$; thus, the maximum cell size is $65 \mathrm{~nm}$, and the minimum cell size was $2 \mathrm{~nm}$.

\section{Results and Discussion}

For UV imprinting, coating the PET with a polymer is a prerequisite procedure, and the nanostructured moth-eye layer was applied using an AAO master mold, which was subsequently compressed against polymer-coated PET film using a roll bar. The sample was cured with the UV light for $30 \mathrm{~s}$ and again for $30 \mathrm{~s}$, once the AAO template had been removed, thus generating a replica moth-eye nanostructure. FE-SEM images of the AAO master mold templates exhibited well-controlled nanocone arrays. The shapes and sizes of the imprinted polymeric moth-eye-like nanostructure arrays were found to depend on the structures of nanopores arrays in AAO template molds. According to the FE-SEM images, only a $\sim 100 \mathrm{~nm}$ structure was found to be eligible to produce a stable embossed polymer mold shape as demonstrated in Figure 2. The neighboring apexes in nanocones appeared to be amalgamated for the 300 and $500 \mathrm{~nm}$ templates in depth, presumably due to their strong van der Waals interactions.

Figure $3 \mathrm{a}, \mathrm{b}$ shows the top-view FE-SEM images of numerous embossed conical shaped polymeric nanostructures prepared using the AAO template with the diameter and depth of $\sim 90 \mathrm{~nm}$ and $\sim 100 \mathrm{~nm}$ based on the results in Figure 2. FE-SEM images indicated that a master mold exhibited a homogeneous morphology. To demonstrate a property of the self-cleaning and self-curing behavior of a moth-eye-like nanostructure, the surface of AAO template was coated by the surface-treatment agents. Figure 3 illustrates FE-SEM images of the polymeric moth-eye nanostructures prepared with the AAO templates. The homogenous morphology of the surface layers is a result of controlling the nanopore array on the PET film with each nanocone measuring $\sim 90 \mathrm{~nm}$ and $\sim 100 \mathrm{~nm}$ in diameter and length, respectively, and $\sim 105 \mathrm{~nm}$ between the two nanocones. Figure $3 \mathrm{c}$, d revealed the concaved polymeric nanostructures using the embossed polymer replica. As indicated from the collapsed structured in Figure 2d,f, the embossed structures may have disadvantages of the possible collapse and amalgamation with the neighboring nanocone structures. Despite somewhat nonuniform shapes, the concaved polymer molds from the embossed replica may be suitable for a certain type of anti-reflective coating. 

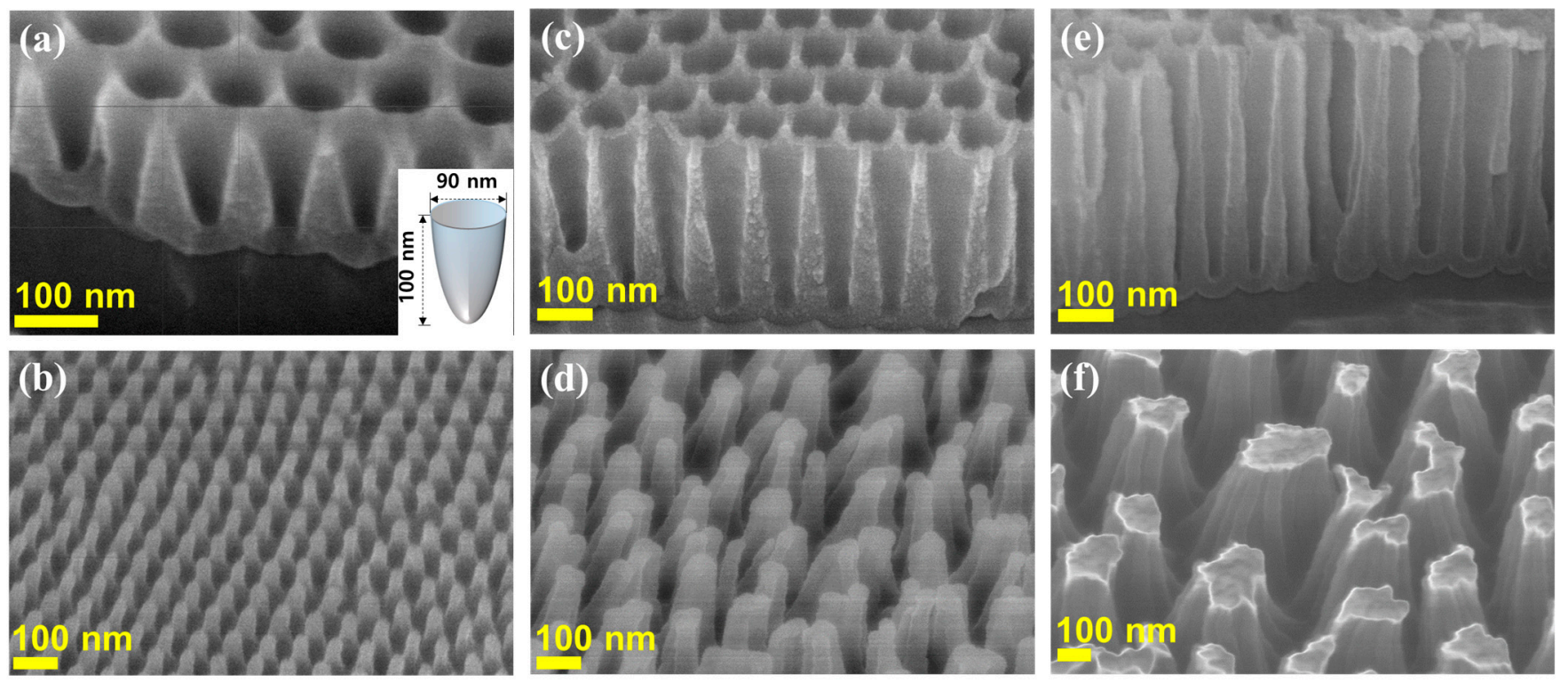

Figure 2. FE-SEM images of the nanocone AAO templates and the resulting moth-eye-like nanostructure from UV-curable polyacrylate urethane resins on a PET substrate with the depths of $(\mathbf{a}, \mathbf{b}) \sim 100,(\mathbf{c}, \mathbf{d}) \sim 300$, and $(\mathbf{e}, \mathbf{f}) \sim 500 \mathrm{~nm}$. All the scale bars are $100 \mathrm{~nm}$. Inserted picture illustrates one nanocone of $\sim 90 \mathrm{~nm}$ in diameter and $\sim 100 \mathrm{~nm}$ in length.
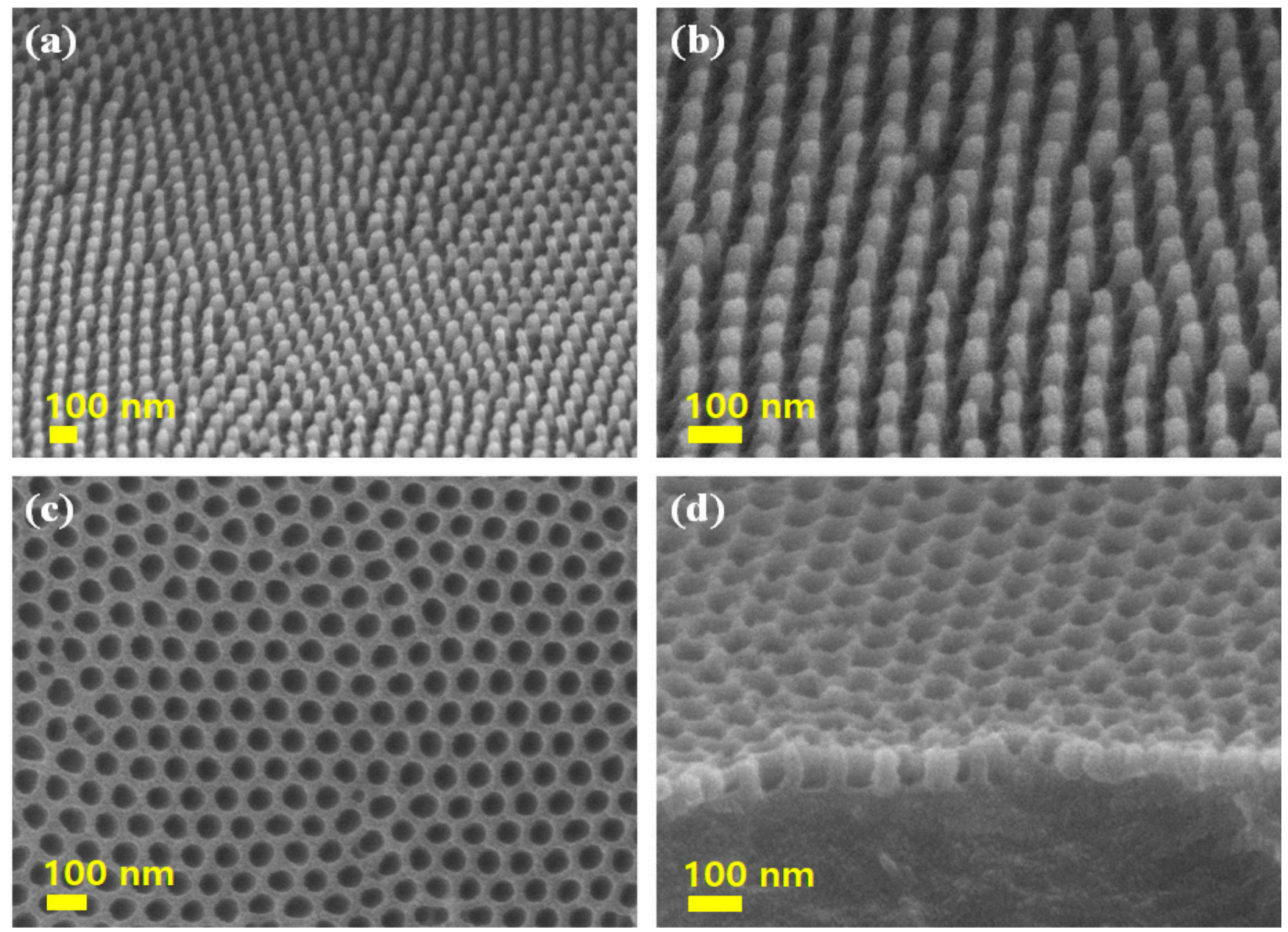

Figure 3. FE-SEM images of $(\mathbf{a}, \mathbf{b})$ embossed and $(\mathbf{c}, \mathbf{d})$ concaved nanostructure using UV-curable polyacrylate urethane resins on a PET substrate after UV irradiation for $30 \mathrm{~s}$, subsequent removal of the AAO template using a fluorine demolding agent, and further UV-curing for $30 \mathrm{~s}$ for. The scale bars are $100 \mathrm{~nm}$. 
Photos of the embossed and concaved anti-reflective polymeric coating structures on the PET substrates with a dimension of $3 \mathrm{~cm} \times 5 \mathrm{~cm}$ are shown in Figure $4 \mathrm{a}, \mathrm{b}$, respectively. AAO surfaces were prepared by anodization to exhibit hydrophobicity, followed by the surface-treatment coating. A water contact angle measurement of the AAO surfaces was estimated that the corner angles of conical-shape structures to be $127^{\circ}$. The current water contact angle measurements of the embossed and concaved polymer surfaces were estimated that the corner angles of conical-shape polymeric structures were $132.5( \pm 2.7)^{\circ}$ and $128.2( \pm 0.9)^{\circ}$, respectively (Figure $4 \mathrm{c}, \mathrm{d}$, Table 1$)$, with a slight increase from the AAO substrates. Before and after the treatment of the surfaces of the AAO templates, the fluorinecontaining surface-treatment polymer had to be introduced to make the polymeric molds superhydrophobic.

(a)

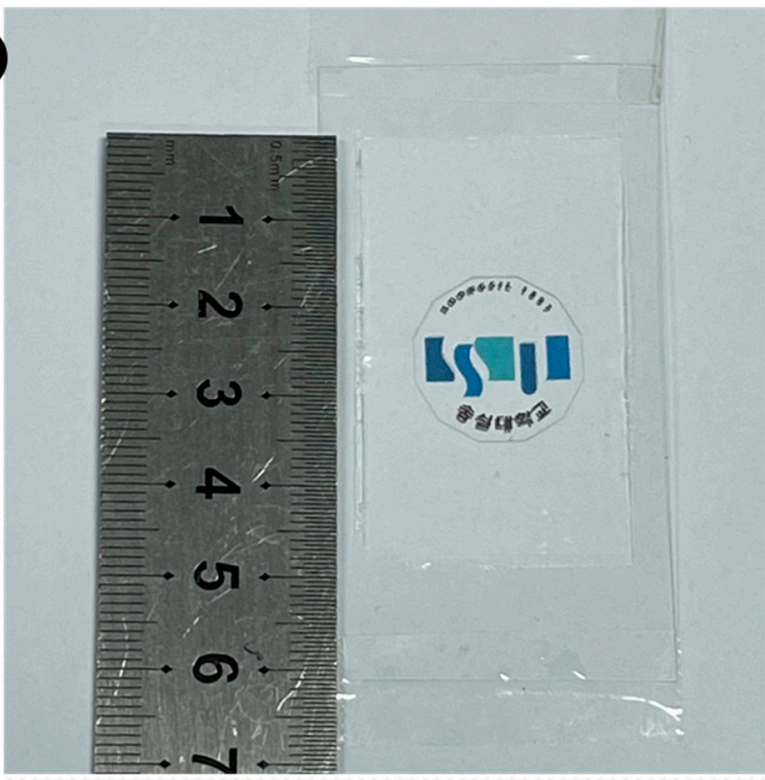

(c)

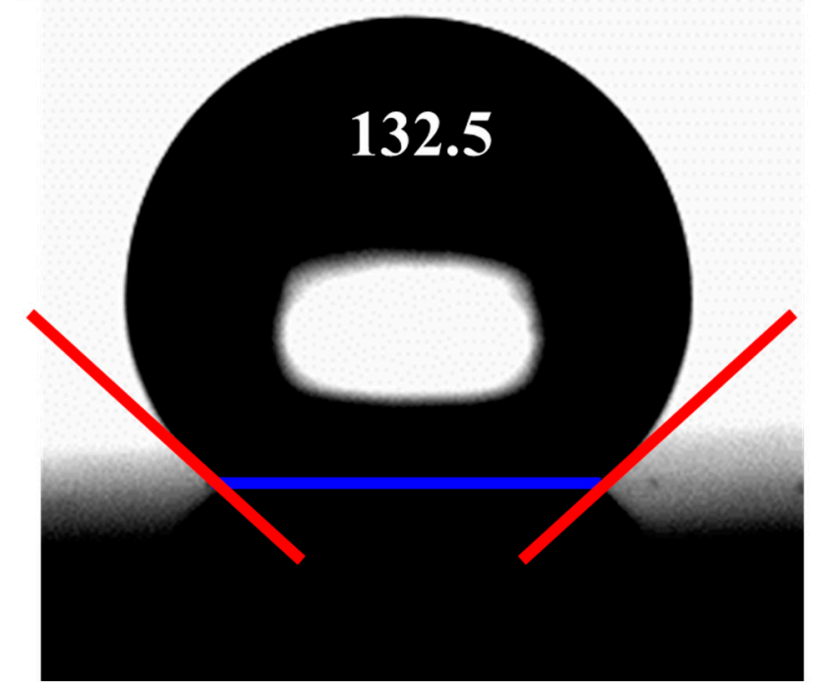

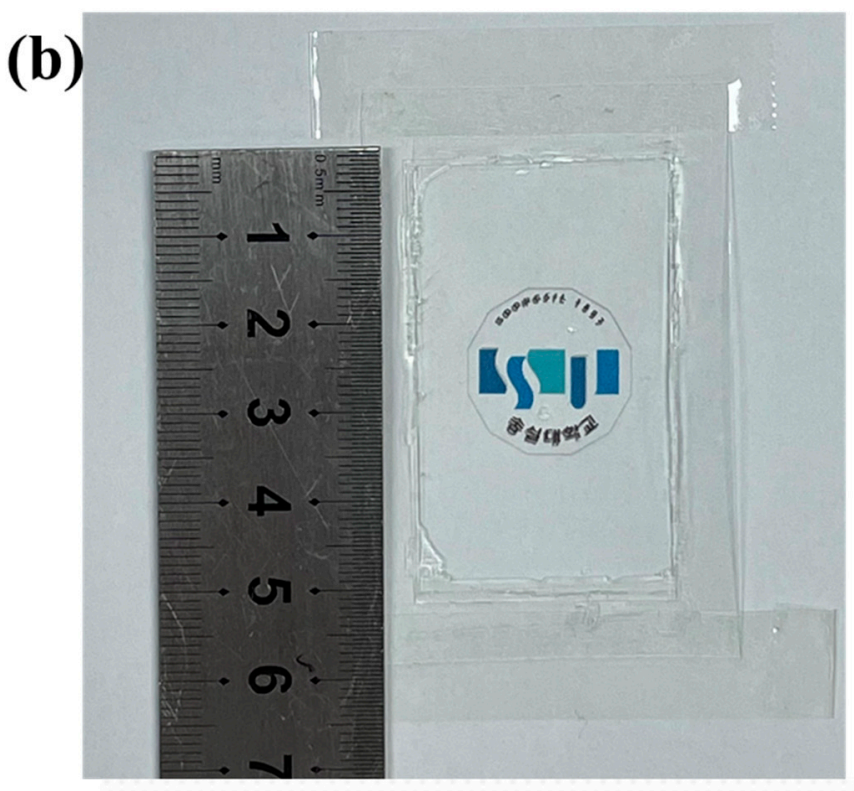

(d)

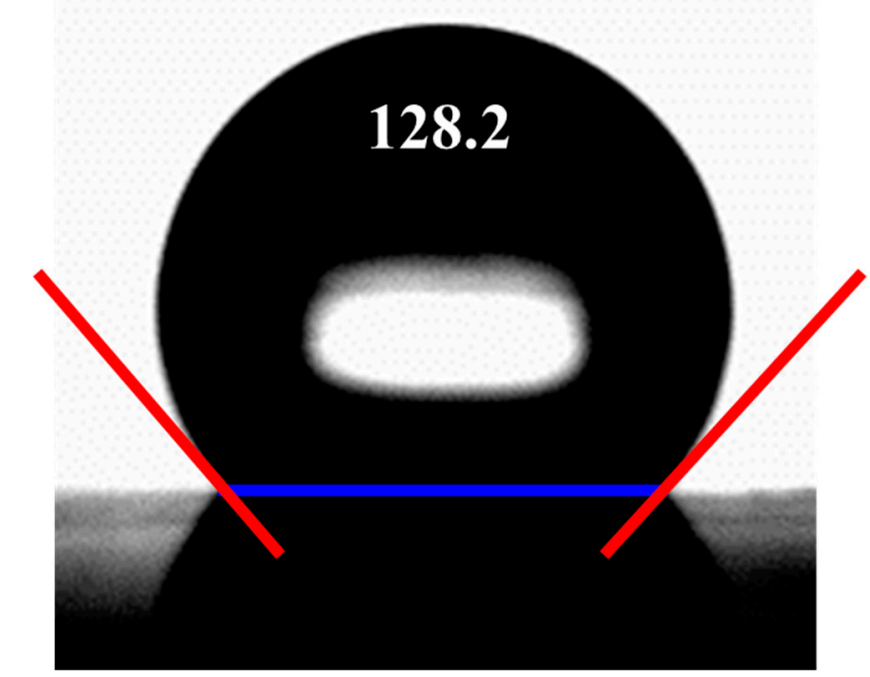

Figure 4. Photos of anti-reflective transparent coating for (a) embossed and (b) concaved polymer mold. Water contact measurements on (c) embossed and (d) concaved polymer mold surfaces, to yield the angles at $132.5^{\circ}$ and $128.2^{\circ}$, respectively. 
Table 1. Measured values of contact angles for the embossed and concaved polymeric mold surfaces. The mean and standard deviations were obtained by 10 independent measurements with the units in degree.

\begin{tabular}{ccc}
\hline & $\begin{array}{c}\text { Replica Embossed Mold } \\
\text { from Master AAO }\end{array}$ & $\begin{array}{c}\text { Concaved Mold from } \\
\text { Embossed Polymer Mold }\end{array}$ \\
\hline Mean & 132.5 & 128.2 \\
\hline Standard deviations & 2.7 & 0.9 \\
\hline
\end{tabular}

Polymeric moth-eye nanostructures have been found to exhibit anti-reflective properties according to previous works [32,33]. In the present experiments, AAO molds were used as imprinting templates to produce polymeric moth-eye nanostructures. UV-curing was applied after the imprinting and the removal of the template. These nanostructure layers can enable efficient practical applications due to their properties including hydrophobicity, flexibility, and transparency. To examine the anti-reflective properties, the absorption and scattering spectra of polymeric moth-eye-like nanostructure were computed using the COMSOL multiphysics software. The results of the simulated spectra of embossed and concaved polymer-based moth-eye-like nanostructures as depicted in Figure 5a,b, respectively, which indicates a negligible absorption, which is verified by almost perfect transmission at $450-800 \mathrm{~nm}$, as shown in the experimental measurements of Figure $5 \mathrm{c}, \mathrm{d}$. The measured transmission values were found to range from $93.4 \%$ to $94.2 \%$ for the embossed polymer molds, whereas they varied from $95.8 \%$ to $96.9 \%$ for the concaved molds in the wavelength region between 500 and $800 \mathrm{~nm}$ (Tables 2 and 3). Notably, the concaved molds showed approximately $2 \%$ higher transmittance values than those of the embossed ones, presumably due to different scattering properties. The concaved mold was found to have a higher scattering cross section in the presented COMSOL calculations. Although not shown here, both the 300 and the $500 \mathrm{~nm}$ conical structure exhibited imperceptible calculated values as that of $100 \mathrm{~nm}$, along with the insignificant absorption above $800 \mathrm{~nm}$ to $2000 \mathrm{~nm}$. Considering that the coating materials in the present study are supposed to be applied in outdoor sensor devices such as a lidar sensor, the high transmission and anti-reflective properties should be suitable for the visible and near-infrared region.

Table 2. Optical transmittance and absorbance values of the embossed polymer replica molds. Ten independent measurements yielded the mean and standard deviation values.

\begin{tabular}{cccccc}
\hline & \multicolumn{5}{c}{ Wavelength } \\
\hline $\begin{array}{c}\text { Transmittance } \\
(\%)\end{array}$ & $\mathbf{4 0 0} \mathbf{~ n m}$ & $\mathbf{5 0 0} \mathbf{~ m ~}$ & $\mathbf{6 0 0} \mathbf{~ n m}$ & $\mathbf{7 0 0} \mathbf{~ n m}$ & $\mathbf{8 0 0} \mathbf{~ n m}$ \\
\hline $\begin{array}{c}\text { Absorbance } \\
\text { (a.u.) }\end{array}$ & $\begin{array}{c}0.044 \\
( \pm 0.014)\end{array}$ & $93.4( \pm 0.6)$ & $94.2( \pm 0.5)$ & $94.0( \pm 0.5)$ & $93.9( \pm 0.5)$ \\
\hline
\end{tabular}

Table 3. Optical transmittance and absorbance values of the engraved polymer replica molds obtained from the embossed polymer replica molds. Ten independent measurements yielded the mean and standard deviation values.

\begin{tabular}{cccccc}
\hline & \multicolumn{5}{c}{ Wavelength } \\
\hline $\begin{array}{c}\text { Transmittance } \\
(\%)\end{array}$ & $\mathbf{4 0 0} \mathbf{~ n m}$ & $\mathbf{5 0 0} \mathbf{~ n m}$ & $\mathbf{6 0 0} \mathbf{~ n m}$ & $\mathbf{7 0 0} \mathbf{~ n m}$ & $\mathbf{8 0 0} \mathbf{~ n m}$ \\
\hline $\begin{array}{c}\text { Absorbance } \\
\text { (a.u.) }\end{array}$ & $\begin{array}{c}0.054 \\
( \pm 0.0048)\end{array}$ & $\begin{array}{c}0.021 \\
( \pm 0.0044)\end{array}$ & $\begin{array}{c}0.017 \\
( \pm 0.0027)\end{array}$ & $\begin{array}{c}0.014 \\
( \pm 0.0014)\end{array}$ & $\begin{array}{c}( \pm 0.013 \\
( \pm 0.001)\end{array}$ \\
\hline
\end{tabular}


(a)

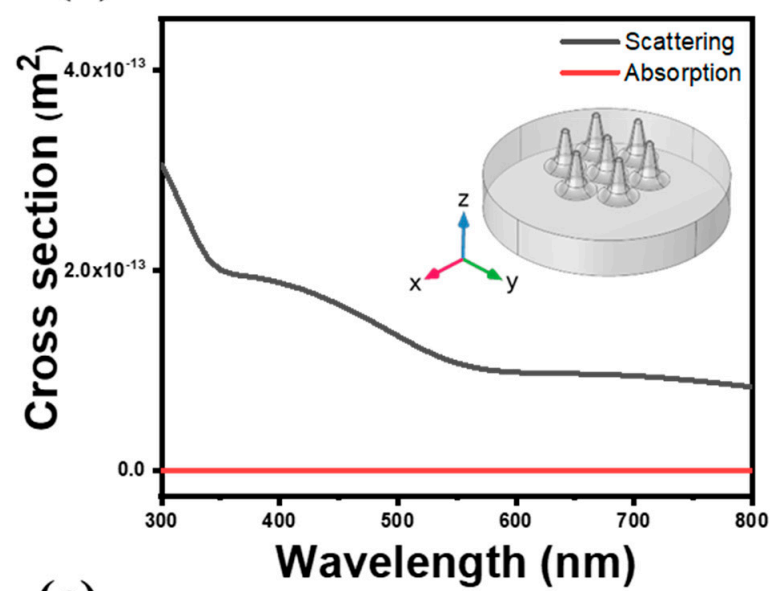

(c)

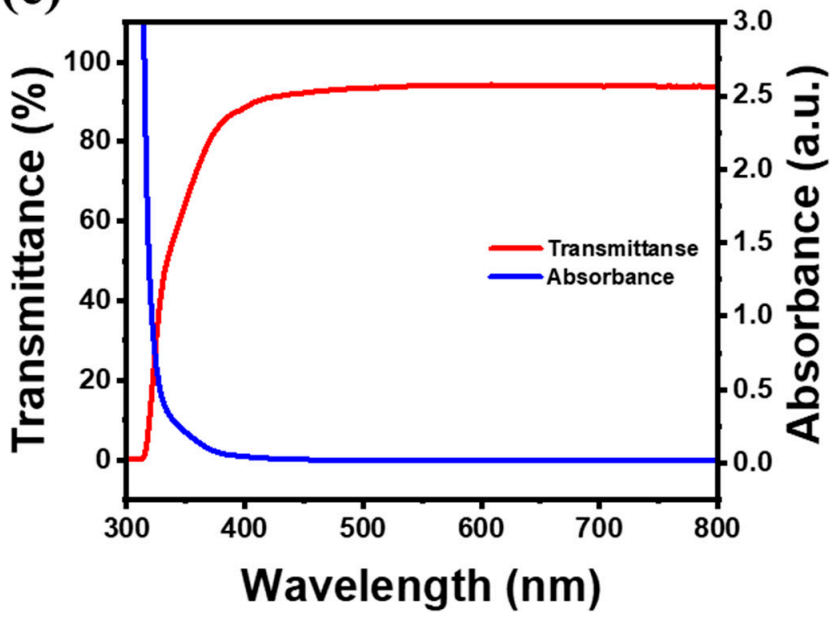

(b)

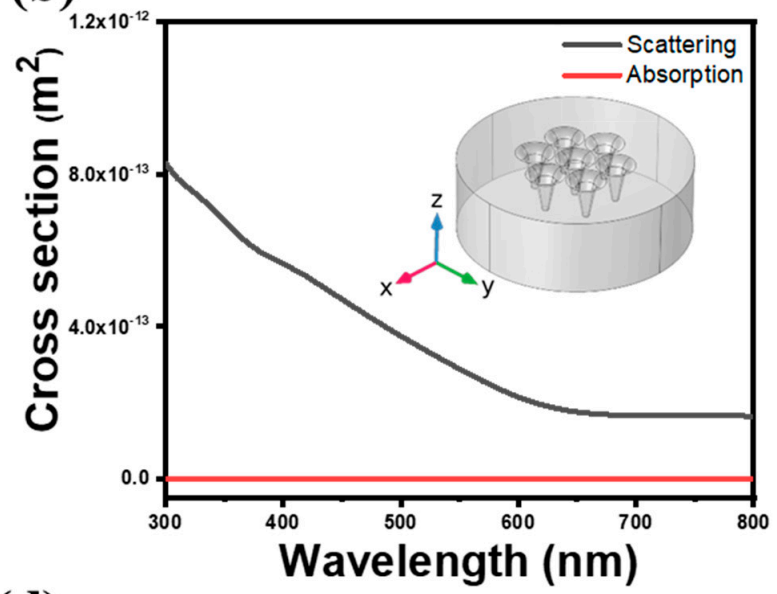

(d)

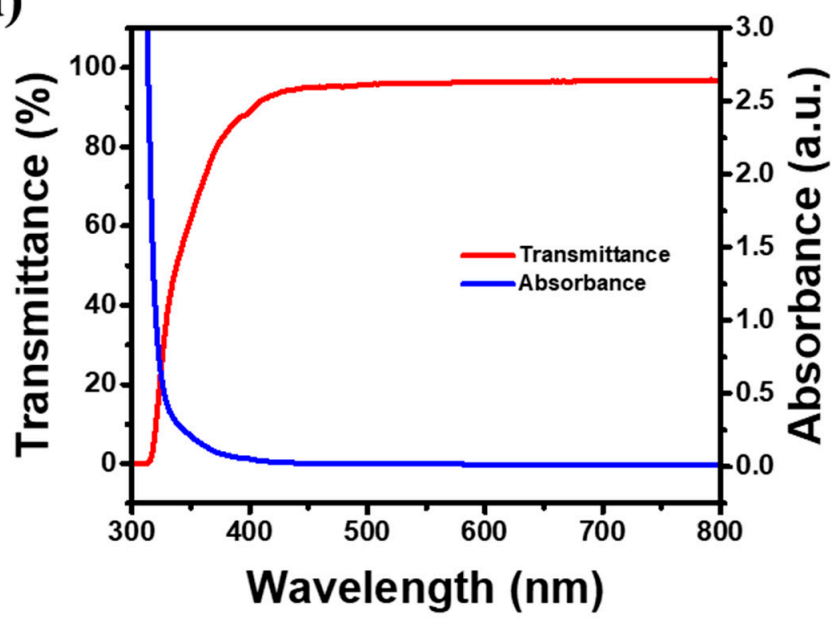

Figure 5. (a) Embossed and (b) concaved polymeric nanostructures in their absorption and scattering curves calculated by the COMSOL multiphysics software. (c) Embossed and (d) concaved polymer nanostructures in their transmission and absorption measurements of the nanostructure polymer as illustrated in the SEM images of Figure 4 showing almost perfect transmission between 450 and $800 \mathrm{~nm}$.

\section{Conclusions}

A moth-eye nanostructured polyurethane acrylate mold was successfully fabricated on a PET substrate using a direct UV imprinting process with the AAO template containing conical shapes. The anti-reflective coating properties of the polymeric layer were evaluated using contact angle measurements, UV-Vis-NIR transmittance, and computer simulations. The following aspects can be summarized from the present study.

- Both embossed and engraved nanopatterned polymeric mold structures were tested for potential applications in transparent coating.

- Only an AAO master mold in the depth of $100 \mathrm{~nm}$ is found to be eligible to produce a stable embossed polymer mold shape.

- The neighboring apexes in nanocones appeared to be amalgamated for the 300 and $500 \mathrm{~nm}$ templates in depth.

- Contact angle measurements of the embossed and concaved polymer surfaces were estimated to be $132.5( \pm 2.7)^{\circ}$ and $128.2( \pm 0.9)^{\circ}$, respectively.

- Concaved molds showed approximately $2 \%$ higher transmittance values than those of the embossed ones.

The developed nanostructures showed promise for real applications due to their antireflection and hydrophobicity. This fabrication method provides a potential technology for designing multifunctional substrates and building moth-eye-inspired materials. The 
anti-reflective layer not only has wide universality but also suggests numerous potential applications in many fields, including flexible display screens, transparent coatings, hydrophobic films, and anti-dazzle glasses.

Author Contributions: Conceptualization, S.H.L. and N.H.L.; experimental and theoretical methodology, J.A.L. and J.E.K.; UV imprint mold investigation, S.-W.L. and V.T.H.; computed COMSOL simulation and supporting polymer resin experiments, N.T.H. and T.-G.T.; writing—original draft preparation, N.H.L.; writing-review and editing, S.J.S. and S.M.N.; commercial application, visualization, and supervision, S.J.S. and S.-W.J. All authors have read and agreed to the published version of the manuscript.

Funding: This research was funded by the National Research Foundation of Korea (NRF) funded by the Korean government (MSIT) (no. 2017R1E1A1A01075141, 2019R1F1A1062685), Korea Basic Science Institute (National Research Facilities and Equipment Center, grant number 2020R1A6C101A184), the Korea Research Institute of Chemical Technology (KRICT) Research and Development (R\&D, SS2141-10) program, and Korea Environment Industry \& Technology Institute (KEITI) through the Technology Development Project for Safety Management of Household Chemical Product Program, funded by the Korea Ministry of Environment (MOE) (2020002970006, 1485017182) and the Ministry of Trade, Industry, and Energy of Korea (20010276).

Institutional Review Board Statement: Not applicable.

Informed Consent Statement: Not applicable.

Data Availability Statement: Data sharing not applicable.

Acknowledgments: The authors would like to thank Se-Jin Choi (MCNet Co., Ltd.) for synthesizing the UV-cure polyurethane arylate resins and surface-treating reagents used in this work and SeungMo Lee and Bok-Hwan Jung for helping experiments and valuable discussion.

Conflicts of Interest: The authors declare no conflict of interest.

\section{References}

1. Ho, T.T.-T.; Dang, C.-H.; Hyunh, T.K.-H.; Hoang, T.K.-D.; Nguyen, T.-D. In situ synthesis of gold nanoparticles on novel nanocomposite lactose, alginate: Recyclable catalysis and colorimetric detection of Fe(III). Carbohydr. Polym. 2021, $251,116998$. [CrossRef]

2. Xiao, Y.; Luo, H.; Tang, R.; Hou, J. Preparation and applications of electrospun optically transparent fibrous membrane. Polymers 2021, 13, 506. [CrossRef] [PubMed]

3. Qaid, S.M.H.; Ghaithan, H.M.; AlHarbi, K.K.; Al-Asbahi, B.A.; Aldwayyan, A.S. Enhancement of light amplification of CsPbBr 3 perovskite quantum dot films via surface encapsulation by PMMA polymer. Polymers 2021, 13, 2574. [CrossRef]

4. Motamedi, M.; Warkiani, M.E.; Taylor, R.A. Transparent surfaces inspired by nature. Adv. Opt. Mater. 2018, 1, 1800091. [CrossRef]

5. Raut, H.K.; Ganesh, V.A.; Nairb, A.S.; Ramakrishna, S. Anti-reflective coatings: A critical, in-depth review. Energy Environ. Sci. 2011, 4, 3779-3804. [CrossRef]

6. Stavenga, D.G.; Foletti, S.; Palasantzas, G.; Arikawa, K. Light on the moth-eye corneal nipple array of butterflies. Proc. R. Soc. B 2006, 273, 661-667. [CrossRef]

7. Córdova-Castro, R.M.; Krasavin, A.V.; Nasir, M.E.; Zayats, A.V.; Dickson, W. Nanocone-based plasmonic metamaterials. Nanotechnology 2019, 30, 055301. [CrossRef]

8. Zhangyang, X.; Liu, L.; Lv, Z.; Lu, F.; Tian, J. The effect of geometry parameters on light harvesting performance of GaN nanostructure arrays-A numerical investigation and simulation. Mater. Res. Express 2020, 7, 015009. [CrossRef]

9. Ko, D.-H.; Tumbleston, J.R.; Henderson, K.J.; Euliss, L.E.; DeSimone, J.M.; Lopez, R.; Samulski, E.T. Biomimetic microlens array with antireflective "moth-eye" surface. Soft Matter 2011, 7, 6404-6407. [CrossRef]

10. Fan, Y.; Song, Y.; He, N.; Cheng, F.; Jiao, X.; Lai, G.; Hua, X.; Yang, X. High efficiency and low migration hyperbranched silicone contain macrophotoinitiators for UV-cured transparent coatings. Polymers 2020, 12, 3005. [CrossRef]

11. Jin, B.; He, J. Self-templated fabrication of robust moth-eye-like nanostructures with broadband and quasi-omnidirectional antireflection properties. ACS Photonics 2016, 4, 188-196. [CrossRef]

12. Zhu, Y.; Shu, L.; Zhang, Q.; Zhu, Y.; Poddar, S.; Wang, C.; He, Z.; Fan, Z. Moth eye-inspired highly efficient, robust, and neutral-colored semitransparent perovskite solar cells for building-integrated photovoltaics. EcoMat 2021, 3, e12117. [CrossRef]

13. Xu, J.; Wang, Z.; Zhang, Z.; Wang, D.; Weng, Z. Fabrication of moth-eye structures on silicon by direct six-beam laser interference lithography. J. Appl. Phys. 2014, 115, 203101. [CrossRef]

14. Xie, S.; Wan, X.; Yang, B.; Zhang, W.; Wei, X.; Zhuang, S. Design and fabrication of wafer-level microlens array with moth-eye antireflective nanostructures. Nanomaterials 2019, 9, 747. [CrossRef] [PubMed] 
15. Tan, G.; Lee, J.-H.; Lan, Y.-H.; Wei, M.-K.; Peng, L.-H.; Cheng, I.C.; Wu, S.-T. Broadband antireflection film with moth-eye-like structure for flexible display applications. Optica 2017, 4, 678-683. [CrossRef]

16. Liu, X.; Li, K.; Shen, J.; Gong, F. Hot embossing of moth eye-like nanostructure array on transparent glass with enhanced antireflection for solar cells. Ceram. Inter. 2021, 47, 18367-18375. [CrossRef]

17. Xie, H.; Xu, W.H.; Jia, S.H.; Wu, T. Tunable fabrication of biomimetic polypropylene nanopillars with robust superhydrophobicity and antireflectivity. Nanotechnology 2021, 32, 395301. [CrossRef] [PubMed]

18. Wang, Z.; Ding, H.; Liu, D.; Xu, C.; Li, B.; Niu, S.; Li, J.; Liu, L.; Zhao, J.; Zhang, J.; et al. Large-scale bio-inspired flexible antireflective film with scale-insensitivity arrays. ACS Appl. Mater. Interfaces 2021, 13, 23103-23112. [CrossRef]

19. Ducros, C.; Brodu, A.; Lorin, G.; Emieux, F.; Pereira, A. Optical performances of antireflective moth-eye structures. Comparison with standard vacuum antireflection coatings for application to outdoor lighting LEDs. Surf. Coat. Technol. 2019, $379,125044$. [CrossRef]

20. Zhao, Q.; Liu, G.; Zhang, H.; Zhou, F.; Li, Y.; Cai, W. SERS-based ultrasensitive detection of organophosphorus nerve agents via substrate's surface modification. J. Hazard Mater. 2017, 324, 194-202. [CrossRef]

21. Liu, J.; Jiao, X.; Cheng, F.; Fan, Y.; Wu, Y.; Yang, X. Fabrication and performance of UV cured transparent silicone modified polyurethane-acrylate coatings with high hardness, good thermal stability and adhesion. Prog. Org. Coat. 2020, 144, 105673. [CrossRef]

22. Park, J.; Lim, T.; Yang, K.H.; Ju, S.; Jeong, S.M. Dipping-press coating method for retaining transparency and imparting hydrophobicity regardless of plastic substrate type. Polymers 2021, 13, 403. [CrossRef] [PubMed]

23. Kim, T.K.; Park, J.S.; Kim, S.H.; Jung, W.T. Structural behavior evaluation of reinforced concrete using the fiber-reinforced polymer strengthening method. Polymers 2021, 13, 780. [CrossRef] [PubMed]

24. Huang, Y.J.; Chang, R.; Zhu, Q.J. Synthesis and characterization of a molecularly imprinted polymer of spermidine and the exploration of its molecular recognition properties. Polymers 2018, 10, 1389. [CrossRef] [PubMed]

25. Jiao, X.; Liu, J.; Jin, J.; Cheng, F.; Fan, Y.; Zhang, L.; Lai, G.; Hua, X.; Yang, X. UV-cured transparent silicone materials with high tensile strength prepared from hyperbranched silicon-containing polymers and polyurethane-acrylates. ACS Omega 2021, 6, 2890-2898. [CrossRef] [PubMed]

26. Othman, N.A.F.; Selambakkannu, S.; Abdullah, T.A.T.; Hoshina, H.; Sattayaporn, S.; Seko, N. Selectivity of copper by amine-based ion recognition polymer adsorbent with different aliphatic amines. Polymers 2019, 11, 1994. [CrossRef] [PubMed]

27. Lee, J.; Hwang, H.S.; Lo, T.N.H.; Koh, W.G.; Park, I. Effect of silica size and content on superamphiphobic properties of silica-fluoropolymer core-shell coatings. Polymers 2020, 12, 2864. [CrossRef]

28. Jahani, Y.; Baena, M.; Gomez, J.; Barris, C.; Torres, L. Experimental study of the effect of high service temperature on the flexural performance of near-surface mounted (NSM) carbon fiber-reinforced polymer (CFRP)-strengthened concrete beams. Polymers 2021, 13, 920. [CrossRef]

29. Lee, H.; Jung, W.T.; Chung, W. Post-tension near-surface mounted strengthening system for reinforced concrete beams with changes in concrete condition. Compos. Part B-Eng. 2019, 161, 514-529. [CrossRef]

30. Seong, K.-D.; Jung, J.-Y.; Kang, J.; Kim, D.-S.; Lyu, L.; Seo, S.; Kim, J.-H.; Piao, Y. Direct printing of high-performance microsupercapacitors on flexible substrates using polymeric stencil masks with highly precise interdigitated patterns. J. Mater. Chem. A 2020, 8, 25986-25994. [CrossRef]

31. Choi, H.S.; Suh, S.J.; Kim, S.W.; Kim, H.J.; Park, J.W. Transparent Electromagnetic Shielding Film Utilizing Imprinting-Based Micro Patterning Technology. Polymers 2021, 13, 738. [CrossRef] [PubMed]

32. Han, G.; Nguyen, T.B.; Park, S.; Jung, Y.; Lee, J.; Lim, H. Moth-eye mimicking solid slippery glass surface with icephobicity, transparency, and self-healing. ACS Nano 2020, 14, 10198-10209. [CrossRef] [PubMed]

33. Han, Z.; Wang, Z.; Li, B.; Feng, X.; Jiao, Z.; Zhang, J.; Zhao, J.; Niu, S.; Ren, L. Flexible Self-Cleaning Broadband Antireflective Film Inspired by the Transparent Cicada Wings. ACS Appl. Mater. Interfaces 2019, 11, 17019-17027. [CrossRef] [PubMed] 